\title{
Migratory Foreign Body Presenting with Thyroid Abscess
}

https://doi.org/10.47210/bjohns.2021.v29i2.440

Sudip Kumar Das, ${ }^{1}$ Chiranjib Das, ${ }^{2}$ Pritam Chatterjee, ${ }^{3}$ Shubhrakanti Sen, ${ }^{4}$ V D Prasanna Kumar Vasamsetty ${ }^{3}$

$\underline{\text { Introduction }}$

ABSTRACT

The most common complication following accidental ingestion of a foreign body is entrapment in the upper digestive tract. Spontaneous penetration of a foreign body through the upper digestive tract and migration into the soft tissues of the neck is very uncommon. Consequences from such migratory foreign body can be serious and potentially fatal.

\section{Case Report}

Thirty six years old female presented with history of accidental ingestion of an unknown foreign body 3 days back. Clinical examination, plain radiography, hypopharyngoscopy and oesophagoscopy failed to find out the foreign body. Thereafter the patient developed thyroid abscess which was confirmed by computed tomography. Surprisingly we discovered the foreign body during surgical exploration of neck.

Conclusion

In a case of accidental ingestion of foreign body, even if initial evaluation with endoscopy and plain radiography are negative, the patient should be followed closely until resolution of symptoms. A high index of suspicion of migration of foreign body should be maintained. Retrieval of migratory foreign body needs surgical expertise and experience..

$\underline{\text { Keywords }}$

Foreign-Body Migration; Abscess; Thyroid Gland

$\mathrm{T}$

The most common complication following accidental ingestion of a foreign body is entrapment in the upper digestive tract. This problem is usually easily diagnosed and treated by otolaryngologists without much difficulty. ${ }^{1}$ However, spontaneous penetration of a foreign body through the upper digestive tract and migration into the soft tissues of the neck is very uncommon. ${ }^{2}$ Diagnosis of migratory

1 - Department of ENT, SSKM Medical College \& Hospital, Kolkata

2 - Department of ENT, Maharaja Jitendra Narayan

Medical College and Hospital, Cooch Behar

3 - Department of ENT, Bankura Sammilani Medical

College \& Hospital, Bankura

4 - Department of ENT, Malda Medical College \& Hospital, Malda

\section{Corresponding author:}

Dr Chiranjib Das

email: chirubata.das.87@gmail.com foreign body at times becomes difficult. Consequences from such migratory foreign body can be serious and potentially fatal. These include formation of deep neck space abscess, puncturing of the carotid artery, ${ }^{3,4}$ internal jugular venous thrombophlebitis, brachial plexus injury and embedment in the thyroid gland..$^{5,6}$ In 1949 Jemerin and Aronoff were the first to report a migratory foreign body in the thyroid gland. ${ }^{5}$ Since then very few cases of ingested migratory foreign bodies have been reported in the thyroid gland. In this article we present such a rare case report of thyroid abscess due to migration of an accidentally ingested foreign body.

\section{Case Report}

Thirty six years old female was admitted through emergency in the ENT department of a tertiary care hospital of West Bengal with history of accidental ingestion of an unknown foreign body 3 days back. On clinical examination patient had severe oedema 


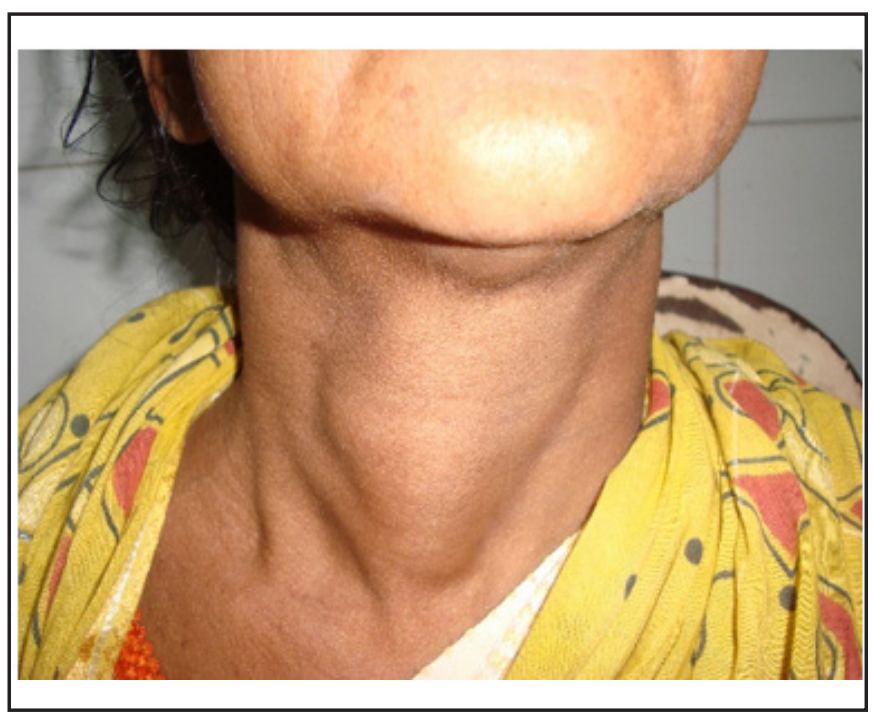

Fig. 1. Clinical photograph showing swelling of right lobe of thyroid gland

of right pyriform sinus but no foreign body could be seen. Inflammation was so extensive that mobility of right hemilarynx was restricted. X-ray soft tissue neck lateral view does not give any conclusive diagnosis. So we started conservative treatment with broad spectrum antibiotics, analgesic and steroid, and planned for diagnostic hypopharyngoscopy and rigid oesophagoscopy under general anaesthesia after oedema had subsided. No foreign body was recovered by hypopharyngoscopy and oesophagoscopy on $7^{\text {th }}$ day. Thereafter the patient had no dysphagia but on $9^{\text {th }}$ day she developed tender swelling of the right lobe of thyroid (Fig. 1). Computed tomography (CT) scan showed abscess cavity in the right upper pole of thyroid gland (Fig. 2).

We decided for surgical exploration of neck keeping in mind that right thyroid lobectomy may be needed. To our surprise we found out the foreign body, a $2.5 \mathrm{~cm}$ long wooden stick inside the abscess cavity at the right superior pole of thyroid gland (Fig. 3). We removed the foreign body with surgical debridement of the abscess cavity (Fig. 4). The patient had an excellent recovery. No complication was noted. Institutional Ethical Committee clearance and informed consent from the patient were taken prior to publication.

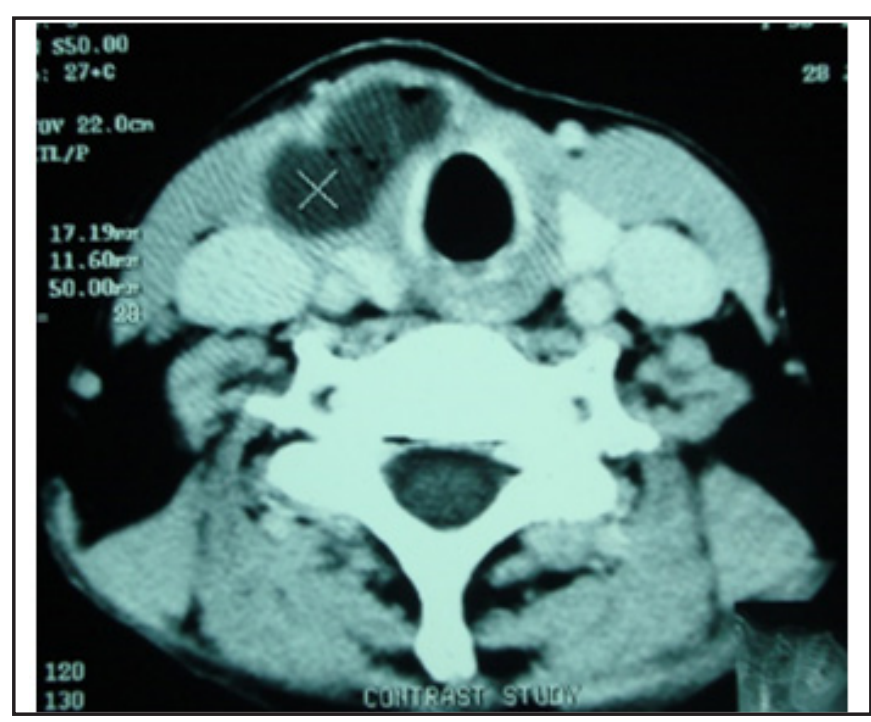

Fig. 2. CT scan axial section showing abscess in the right lobe of thyroid gland

\section{Discussion}

Majority of the accidentally ingested foreign bodies become impacted in the tonsils, base of tongue or vallecula and can be easily removed in the clinic. In few cases the foreign body becomes entrapped at one of the constrictions of the oesophagus, requiring removal by rigid oesophagoscopy under general anaesthesia. In even fewer cases, the foreign body penetrates the oesophageal mucosa and migrates through it into the soft tissues of the neck. The mechanism that causes migration of the foreign body is unknown. ${ }^{5,6}$ It is postulated that combination of oesophageal peristalsis and neck movement is the reason behind migration. ${ }^{7}$ Migration is assumed to have occurred when the foreign body or any type of complication related to foreign body is documented radiographically with negative endoscopy. ${ }^{8}$ Migratory foreign body can remain silent, extrude through the skin or cause serious complications. ${ }^{9}$ Main complications of foreign body migration include formation of deep neck space abscess, puncturing of the carotid artery, ${ }^{3,4}$ internal jugular venous thrombophlebitis, brachial plexus injury, and embedment in the thyroid gland. ${ }^{5,6}$

The incidence of accidentally ingested foreign bodies penetrating the oesophagus and going extra luminal into the neck and forming a neck abscess is less than $1 \% .^{10}$. The foreign body paves the way for bacteria to enter into 


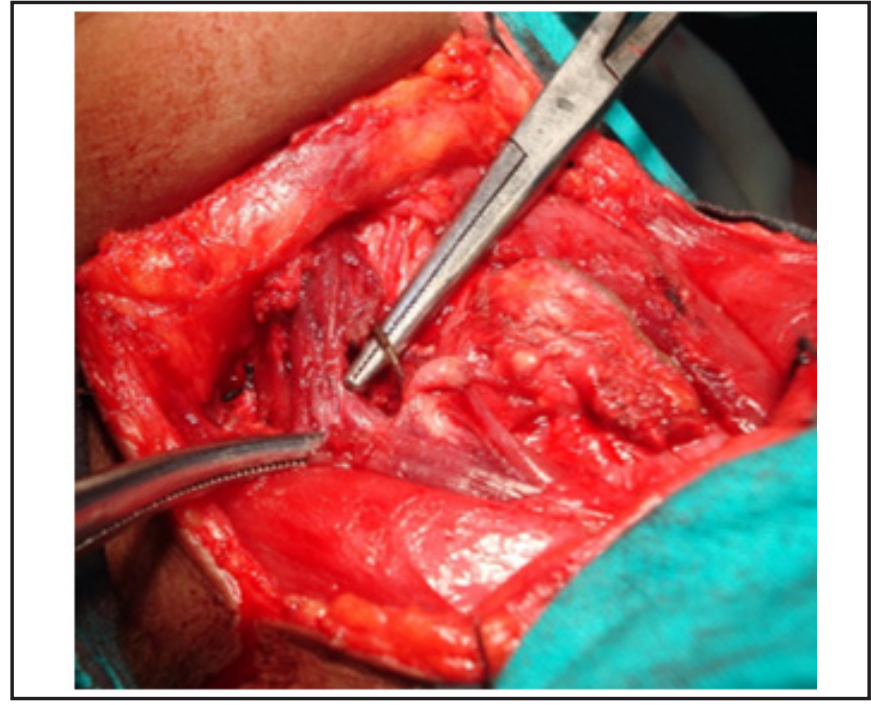

Fig. 3. Intra-operative photograph showing the foreign body at the right superior pole of thyroid gland

the soft tissues of the neck. ${ }^{11}$ Goh and Tan over a period of 11 years described a series of four cases of migration of fish bone into the thyroid gland. All of these were successfully removed by neck exploration with only one case requiring thyroid lobectomy. ${ }^{12}$

$\mathrm{CT}$ scan is superior to a plain radiograph in terms of its ability to identify ingested foreign bodies. CT scan can reveal not only the size, type, location, and orientation of the foreign body, but also its relationship to other vital structures of the neck, and estimate the extent of damage done8.

In the present case, the patient couldn't describe the nature of the accidentally ingested foreign body and it was also not apparent on plain radiograph. The only clue of migratory foreign body in this case was finding of abscess cavity in the right upper pole of thyroid gland on CT scan.

Management migratory foreign body involves exploration of the neck by an external approach and removal of the foreign body. Exploration for a migratory foreign body has been described by some otolaryngologists to be like fishing for a needle in the ocean. The main difficulty during exploration is the localization of the foreign body in the soft tissues of the neck. The foreign body at the time of surgery may not be located exactly where it is shown to be in the CT scan

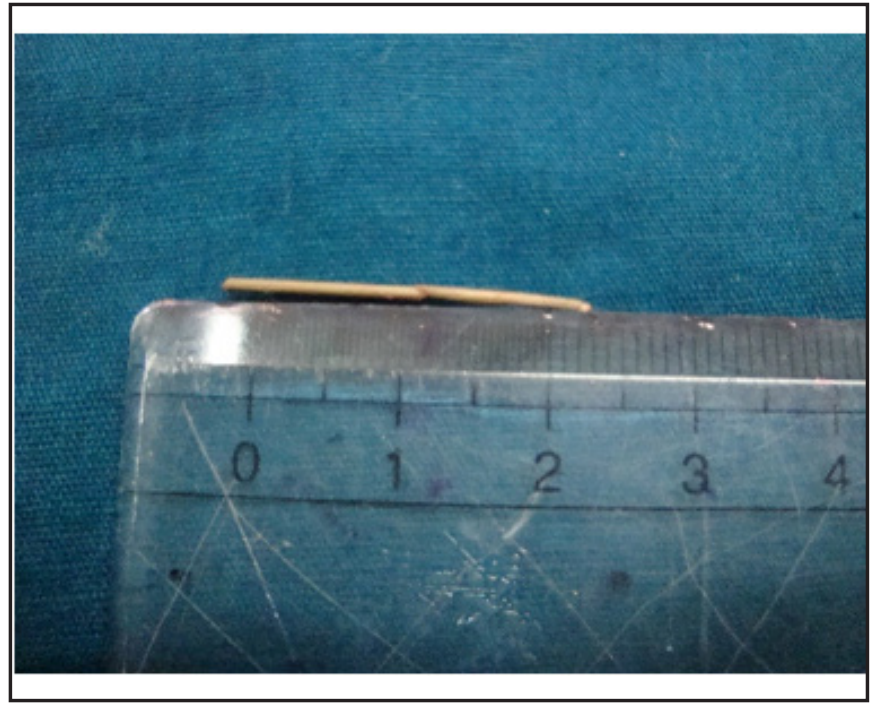

Fig. 4. Photograph of the retrieved foreign body (wooden stick)

as the soft tissues of neck are mobile in relation to the bony and cartilaginous structures. ${ }^{12}$ Meticulous surgical technique and experience of the surgeon are crucial for a successful outcome.

\section{Conclusion}

In a case of accidental ingestion of foreign body, even if initial evaluation with endoscopy and plain radiography are negative, the patient should be followed closely until resolution of symptoms. A high index of suspicion of migration of foreign body should be maintained. Retrieval of migratory foreign body needs surgical expertise and experience.

\section{References}

1. Leong HK, Chan RKC. Foreign bodies in the upper digestive tract. Singapore Med J. 1989; 28:162-5

2. Nandi $\mathrm{P}$, Ong GB. Foreign body $m$ the oesophagus: Review of 2394 cases. Br J Surg. 1978; 65(1):5-9

3. Clerf LH. Foreign bodies in the air and food passages: observations on end-results in a series of nine hundred and fifty cases. Surg Gynae Obstet. 1940; 70:328-39

4. Yang CY. The management of ingested foreign 
bodies in the upper digestive tract: A retrospective study of 49 cases. Singapore Med J. 1991; 32:312-5

5. Jemerin EF, Aronoff JS. Foreign body in the thyroid following perforation of oesophagus. Surgery 1949; 25:52-9

6. Muhanna AA, Abu Chra KA, Dasti H, Behbehani A, Al-Naqeeb N. Thyroid lobectomy for removal of a fish bone. J Laryngol Otol. 1990; 104(6):511-2

7. Tang IP, Singh S, Shoba N, Rahmat O, Shivalingam S, Gopala KG, Khairuzzana B. Migrating foreign body into the common carotid artery and internal jugular vein-a rare case. Auris Nasus Larynx 2009; 36(3):380-2

8. Chee LW, Sethi DS. Diagnostic and therapeutic approach to migrating foreign bodies. Ann Otol
Rhinol Laryngol. 1999; 108:177-80

9. Remsen K, Lawson W, Biller HF, Som ML. Unusual presentations of penetrating foreign bodies of upper GIT. Ann Otol Rhinol Laryngol Supp. 1983; 105:32-44

10. Lam HC, Woo JK, van Hasselt CA. Esophageal perforation and neck abscess from ingested foreign bodies: Treatment and outcomes. Ear Nose Throat J. 2003; 82(10):786-94

11. Goh YH, Tan NG. Penetrating oesophageal foreign bodies in the thyroid gland. J Laryngol Otol. 1999;113:769-71

12. Lu PK, Brett RH, Aw CY, Singh R. Migrating Oesophageal Foreign Body- An Unusual Case Singapore Med J. 2000; 41(2):77-9. 